\title{
Enabling the digital fashion consumer through fit and sizing technology
}

DOI:

10.1080/20932685.2017.1399083

\section{Document Version}

Accepted author manuscript

Link to publication record in Manchester Research Explorer

\section{Citation for published version (APA):}

Miell, S., Gill, S., \& Vazquez, D. (2018). Enabling the digital fashion consumer through fit and sizing technology. Journal of Global Fashion Marketing, 9(1), 9-23. https://doi.org/10.1080/20932685.2017.1399083

\section{Published in:}

Journal of Global Fashion Marketing

\section{Citing this paper}

Please note that where the full-text provided on Manchester Research Explorer is the Author Accepted Manuscript or Proof version this may differ from the final Published version. If citing, it is advised that you check and use the publisher's definitive version.

\section{General rights}

Copyright and moral rights for the publications made accessible in the Research Explorer are retained by the authors and/or other copyright owners and it is a condition of accessing publications that users recognise and abide by the legal requirements associated with these rights.

\section{Takedown policy}

If you believe that this document breaches copyright please refer to the University of Manchester's Takedown Procedures [http://man.ac.uk/04Y6Bo] or contact uml.scholarlycommunications@manchester.ac.uk providing relevant details, so we can investigate your claim.

\section{OPEN ACCESS}




\title{
Enabling the Digital Fashion Consumer through Fit and Sizing Technology
}

\author{
Miell, S., Gill, S. \& Vazquez, D.
}

Design and Fashion Business, School of Materials, University of Manchester, United

Kingdom.

Sophie Miell

The University of Manchester

Email: sophie.miell@manchester.ac.uk

Dr Simeon Gill

The University of Manchester

Email: simeon.gill@manchester.ac.uk

Dr Delia Vazquez

The University of Manchester

Email: delia.vazquez@manchester.ac.uk 


\begin{abstract}
Online fashion retailing is a major growth area. Innovative online fit and sizing technologies that facilitate purchase continue to develop and launch, however, problems associated with digital expectations of fit and size in consumer decision-making, remain unresolved. This research focuses on 20 prominent fit and size technologies from a sample of 30 , and uses content analysis to examine website design and operation. Content analysis combined with an extended literature review enables the linking of academic theory and practice. The research provides discussion for best-practice utilisation of fit and sizing technology through the Omni-fit model, which accounts for the combination of technological approaches, and the emerging influence of augmented and virtual reality fashion technology. The results include the need for improvements to 3D visualisation, user experience, and online customer relationship management of existing websites, aligned with Omni-channel retailing practice.
\end{abstract}

Keywords: Fit and Sizing Technology, Omni-Channel Retailing, Augmented Reality, Virtual Reality, Fashion marketing

\title{
EXTENDED ABSTRACT
}

The online fashion retailing industry has evolved considerably since its launch. Through the dotcom bubble and bust, fuelled by the prevalence of mobile and technological development, and now towards the Omni-channel retailing environment of today (Verhoef, Kannan, \& Inman, 2015). A stream of new enabling fit and sizing fashion technologies have become available to consumers, across all sectors. Consumers have greater access to online channels, products, and retailers (Labrecque, vor dem Esche, Mathwick, Novak, \& Hofacker, 2013). An inevitable facet of prolific digital growth and reduced loyalty is the effect on increasing product returns and subsequent diminished consumer satisfaction, which are estimated to cost UK retailers £60bn a year (Financial Times 2016). 
One way retailers have been aiming to solve the problem of returns and the lack of tactile experience online, is through online virtual fitting rooms and sizing technology (Blázquez, 2014). The area of virtual fit and sizing has been approached in research by a variety of disciplines including garment technology, consumer behaviour or marketing. This study provides cohesion amongst the co-existing areas of fit and sizing research, summarises academic, marketing, and developer perspectives and bridges the gap between research and industry.

There are a number of challenges associated with digital fit and sizing technology making the area problematic for research. Size and fit interfaces rely on consumer acceptance for success and without the necessary technology and development driving such interfaces, their accuracy may be limited. More recent approaches to tackling fit, styling, and sizing issues involve algorithmic approaches, also referred to as collaborative filtering in recommender systems (Chung \& Rao 2012), which use machine learning to develop an accurate idea of a user's preferences. Another challenge in the field of fit and sizing is the need for the synthesis of technical garment interfaces and consumer fit and sizing preferences into a singular understandable interface. This study adopts a content analysis (Krippendorff 2004) and extended literature review method of 20 fit, size, and style websites. Interfaces were coded and counted based on their layout, format, function, and channel with a greater focus on B-2C interfaces. The interface features were categorised into three predominant areas, fit visualisation, fit recommendation, and size recommendation. Analysis shows that the areas included overlap and findings recognise the need to utilise aspects of all three interface categories for the most successfully optimised future platforms.

The discussion is summarised in the Omni-fit model, which accounts for the existing areas of virtual fit, e-size, and style websites, along with necessary areas for development. 
Future areas of research are also summarised in the model, where fit and sizing technology can be used with Augmented or Virtual Reality Technology.

\section{Introduction}

The UK online fashion industry is expected to reach $£ 28.9 \mathrm{~m}$ by 2022 , with clothing taking around a quarter of total UK fashion sales (Mintel 2017). The physical store is however still used by consumers as a channel to browse products prior to purchase (Mintel 2017). Digital fit and sizing technologies exist as a function within a retailer website or mobile application. Fit and sizing interfaces are intended to assist or guide online consumers to make a product purchase on fit, size, or style criteria. Providing an accurate digital depiction of clothing on the body prior to purchase could reduce consumer uncertainty, decrease return rates, and strengthen the effectiveness of the online retailing channel. However, returns remain at around 50\% of all online sales according to Mintel (2017), as online platforms have to overcome inherent difficulties with the lack of tactility in clothing selection. This research critically discusses gaps in areas of previous research in fit and sizing technology through a literature review. The literature review establishes research areas to guide interface cues assessed through the content analysis. The research undertakes a detailed content analysis of existing interfaces to understand format and online delivery (Table 1). The research makes recommendations for how the interfaces can be developed to best serve online fashion consumers in the future which are summarised in a model (Figure 1). Finally, the research identifies managerial implications and areas for future research studies in fit and sizing technology.

\section{Literature Review}

Research conducted in the area of fit and sizing technologies is rarely undertaken in a holistic way. Existing studies approach the area from either a technologist perspective or a consumer behaviour perspective. This study initially divides the literature into two areas, virtual 
clothing technology and digital consumer behaviour. Dividing the literature was necessary to understand both the technical and consumer inputs driving the existing technology. The approaches from literature are combined and included in the results and model (Figure 1). This synergy is necessary in order to guide future research. The following section will critically discuss the existing research approaches.

\subsection{Virtual Clothing Technology Literature}

Research in the area of virtual clothing technology uses the simulation of garment fit in digital product development or computer aided manufacture (CAM). 3D body scanning is often used as the measurement method of previous virtual clothing technology research (Loker, Ashdown, \& Carnrite, 2008; Loker, Cowie, Ashdown, \& Lewis, 2004). Despite not being available for use in consumer online purchasing contexts, virtual clothing technology research provides insight into the use of 3D body scanning which is a key tool for placing the

consumer into accurate digital environments. 3D body scanning has been of interest to retailers and interface developers due its efficiency of capturing human measurements (Song \& Ashdown 2012) and its potential for future use in digital consumer tools. Kim and LaBat (2013) and Song and Ashdown (2015) use the comparison of real and virtual (3D body scan) fit, and highlight the conflict between real fit experiences and those in simulated environments. Virtual clothing technology software does little to extend to the use of 3D visualisation used in consumer contexts. Therefore, testing consumer acceptance is an area that needs to be further explored. Moreover, the language used by technologists and consumers has not been compared in previous research. Comparing the language used to describe fit from multiple perspectives (technologist and consumer) would enable the development of a mutual language of fit into an understandable and useful tool for any clothing fit analysis. 
Song and Ashdown (2015) highlight that the use of body scanned avatars in the context of pattern making and cloth simulation has been limited to retailers and manufacturers in digital prototyping and design of garments. Despite technologist usage, research using participant body scanned avatars to assess fit (Kim \& LaBat, 2013; Song \& Ashdown, 2015) highlight that the computation of virtual fabrics are inaccurately depicted. Problematic areas of fit such as the crotch are found to be difficult to portray digitally. Despite assumptions that virtual clothing technology would be more technologically advanced in accuracy than consumer based technology, clothing visualisation software still requires further development to enhance graphic depiction.

One way consumer body scanning outputs are used in previous research is through the collection of body scan databases which are also used in the development of virtual fit websites that are available to consumers (Gill 2015). This alludes to the future potential use of commercial 3D scanned avatars in developing interfaces. Participant reactions to 3D body scans is a complex area due to the psychological and emotive implications of visualising the body in 3D (Loker et al., 2008, 2004). Studies in this area conclude with negative consumer responses (Grogan, Gill, Brownbridge, Warnock, \& Armitage, 2016). Therefore, this is another area that needs to be developed to increase consumer willingness to be 3D body scanned.

\subsection{Digital Fashion Consumer Behaviour Literature}

Digital fashion consumer technology is a form of image interactivity technology (IIT) (Lee, Kim, \& Fiore, 2010). Digital fashion technology can include augmented reality (AR) visualisation technology, which relates to the overlaying of a virtual garment on an avatar (Javornik 2016). In-store virtual mirror technology is an emerging form of AR with promise to enhance in-store convenience (Perry 2016). The impact of virtual mirrors is related to the development of online virtual dressing rooms as they facilitate consumer experience of 
virtual fitting where social interactions are present (Yaoyuneyong, Foster, \& Flynn, 2014). Further research into the role of social interactions during innovative retail experiences is also required (Pantano \& Gandini 2017). Empirical understanding of consumer experience when using the technology either in store or online is also needed as there are a limited number of previous studies in the area.

Studies that have assessed the area of online fit and sizing technology have stopped at consumer purchase intention when using the interface (Lee et al., 2010). An outcome of digitally assisted fit and sizing decision making is that consumers may be willing to pay more to use avatars when shopping online (Kim \& Forsythe 2008). This finding provides grounds for investigating the area to enhance consumer adoption and profit. Lemon and Verhoef (2016) state that the impact of the post-purchase satisfaction can inform future experiences. A deeper understanding of post-purchase could be gained by using virtual methods to clothing fit and contrasting with physical try-on in the store, an approach that no prior studies have adopted. Using this method, the real and digital expectations of the garment can be compared and consumer loyalty can also be identified through post-use evaluation.

Shim and Lee (2011) and Merle et al. (2012) indicated that avatars could increase entertainment, perceived value, and satisfaction. These research studies discuss the hedonic benefits associated with experiencing 3D products. Similarly, studies that have used the Technology Acceptance Model (Davis, 1989) as a theoretical framework and have found that perceived enjoyment was more important in the use of virtual technology than perceived usefulness (Beck \& Crié 2016; Pantano \& Servidio 2012). Future exploration of fit and sizing technology should consider whether the technology can be a utilitarian and hedonic tool to purchase. When analysing new virtual shopping/augmented reality apps and mirrors, research should consider whether these technologies serve to increase sales revenue, decrease returns, or are merely a consumer engagement tool. 


\subsection{Research Approach for Content Analysis}

The content analysis was undertaken to explore how existing fit and sizing interfaces serve the needs of retailers and consumers. The interface analysis was undertaken framed by existing classifications developed through previous analysis by Gill (2015). Current interfaces can be classified as either size recommendation, fit visualisation, or fit recommendation (Gill 2015). These classifications developed from the outputs of the interfaces based on consumer data, where consumers are either recommended a specific size, or range of sizes, recommended a garment from visualisation methods related to its fit, or recommended a fit from a variety of sizes with criteria related to how the consumer finds would find the fit. The classifications whilst distinct, can be seen to cross over in the interfaces and show a need to develop more robust classifications, which this work seeks to do. This is clear from the literature review, where studies often use a single interface and approach, with little discussion of the range of approaches to mediate product selection through online methods.

\section{Research Method}

As fit and sizing technologies are relatively under-researched, content analysis was selected to enable a research process that would explore the interfaces and provide a theoretical base (Lai \& To 2014) which is currently missing in previous fit research and discussion. Content analysis allows a condensed and understandable method of deducing data from a source (Elo \& Kyngäs, 2008) and is suited to addressing the varied interfaces provided to support online clothing selection. Documentation of such changes through coding the website features can reveal how and when new websites are developed and how future strategies may be devised (Marciniak and Bruce 2004; Krippendorff 1989; Kim and Kuljis 2010) (Table 1). Additionally, content analysis enabled a clear outlining of interface design, level of maturity, 
and direction of development (Ellis-Chadwick, Doherty, \& Hart, 2002; Marciniak \& Bruce, 2004).

Table 1. Content analysis data

\begin{tabular}{|c|c|c|}
\hline Criteria content & Option & $f$ \\
\hline \multicolumn{3}{|l|}{ Website/application format } \\
\hline \multirow[t]{4}{*}{ Platform } & $\mathrm{PC}$ & 15 \\
\hline & Mobile & 1 \\
\hline & Application & 5 \\
\hline & PC \& Mobile & 4 \\
\hline \multicolumn{3}{|l|}{ Type of interface } \\
\hline \multirow[t]{3}{*}{ Primary Category } & Size Recommendation (SR) & 6 \\
\hline & Fit Recommendation (FR) & 1 \\
\hline & Fit Visualisation (FV) & 8 \\
\hline \multirow[t]{4}{*}{ Secondary Category } & $\mathrm{SR}+\mathrm{FR}$ & 2 \\
\hline & $\mathrm{FV}+\mathrm{SR}$ & 1 \\
\hline & $\overline{F R}+\mathrm{FV}$ & 1 \\
\hline & $\mathrm{SR}+\mathrm{FR}+\mathrm{FV}$ & 2 \\
\hline \multirow{3}{*}{$\begin{array}{l}\text { Retailer or User based (Indepdent User } \\
\text { Profiles, Retailer dependent profiles, Industry } \\
\text { application) }\end{array}$} & Independent user profiles & 9 \\
\hline & Retailer dependent profiles & 6 \\
\hline & Industry application & 2 \\
\hline \multicolumn{3}{|c|}{ Input Criteria } \\
\hline \multirow[t]{3}{*}{ Gender } & Male & 0 \\
\hline & Female & 6 \\
\hline & Unisex & 15 \\
\hline \multirow[t]{6}{*}{ Initial Measurements } & Height & 10 \\
\hline & Weight & 10 \\
\hline & Age & 3 \\
\hline & Bra Size & 5 \\
\hline & Bust Size & 5 \\
\hline & Waist & 4 \\
\hline \multicolumn{3}{|l|}{ Body shape options } \\
\hline Figure & Belly shape/tummy shape/stomach type & 3 \\
\hline \multirow[t]{8}{*}{ Classifcations } & Shoulder width & 1 \\
\hline & Hip shape & 1 \\
\hline & Torso type & 1 \\
\hline & Pear & 3 \\
\hline & Hourglass & 3 \\
\hline & Cone & 3 \\
\hline & Apple & 1 \\
\hline & Straight & 1 \\
\hline \multicolumn{3}{|l|}{ Avatar Aesthetics } \\
\hline \multirow[t]{2}{*}{ Avatar Correction } & Yes & 7 \\
\hline & No & 2 \\
\hline \multirow[t]{4}{*}{ Avatar Personalisation } & Face/ skin type & 3 \\
\hline & Hair & 3 \\
\hline & Makeup & 1 \\
\hline & No & 5 \\
\hline
\end{tabular}

Sample: 20 Websites and applications

$\boldsymbol{f}=$ frequency

The sample used three methods; Firstly, internet searches using interface keywords (e.g. virtual fitting room), secondly, social media articles on the area and thirdly, online news sources that focused on emerging fit and sizing technologies and interfaces that were partnered with retailers. Of the 30-functional fit and sizing websites found, 20 were selected 
as they were leading examples of the B-2-C websites accessible to UK consumers. These websites fundamentally enabled product purchase, some with notable fashion retailers. A systematic analysis of the interfaces was undertaken between December 2014 and February 2016 to note developments, newly released interfaces, and allowed for the capture of interfaces which were unsuccessful over time. The websites were classified primarily by their focus against initial criteria from Gill (2015) for example size recommendation or fit visualisation (see "type of interface” Table 1) and were further classified based on format and platform e.g. mobile or PC and their consumer offering (see "format" and "input criteria" Table 1). Counts of each content cue discussed above are included in Table 1 . The frequency number in Table 1 indicates the number of websites using the listed content cues and allows for discussion regarding common traits found in the interfaces. Due to the varied nature of the interfaces available and different features, each section of content cues may not always represent the total sample. Analysis focused on the staging of the interface and the data presented to and required by users. Results were recorded into Excel and coded against established criteria and further considered against criteria identified during data collection. Salient areas identified provided the framework which summaries and comparison of typologies were made and are discussed in the results (Table 2). Key thematic analysis enabled commonalities to be identified as well as particular individual strengths that might be highly successful and could enhance all interfaces by their inclusion.

\section{Content Analysis Results \& Discussion}

Analysis of the existing fit and sizing technologies confirmed the three primary categories (Gill 2015) a. Size Recommendation, b. Fit Recommendation and c. Fit Visualisation (Table 2). Multi-functional attributes of fit and sizing websites suggest a need to expand from this initial criterion to recognise the complexity of interfaces against theory. The results are displayed in order of weighting (Table 2) and show that size and style recommendation was 
the most common format of fit and sizing technologies analysed (42\%). Size and style recommendation websites are considered to impart the least risk for both retailer and the consumer as the interface uses existing sizing charts to map predictions based on the user's preferences. This method does not consider the greater complexity of the body and the nuances of fit within an avatar. Conversely, the results showed that fit recommendation held the smallest percentage of web formats (8\%), which is due to the complexity of technology and the need for a simplistic method of portraying fit for consumers to understand (supported by discussion in section 2.1 of this research). Fit-related interfaces therefore need to be simple yet accurate enough to incentivise consumers to adopt them.

\subsection{Size and Style Recommendation}

Size and style recommendation websites use questions (linked to algorithms) to provide the user with a size or garment recommendation. The prerequisite questions varied across interface developer, including classifications for style preference, body esteem, and body satisfaction as found in other research (Shin \& Baytar 2013). Examples of size and style technologies include style advice to make the platform more credible. These tools allow for the monitoring of browsing, recording likes and dislikes, and a fuller understanding of individual consumer purchase choices. Size and style recommendation can therefore utilise the most effective methods of customer acquisition and retention and provide more personalised experiences (Wedel \& Kannan 2016). Inherent issues with data management pertaining to company capabilities and the increasing awareness of consumer privacy concerns will be a barrier to growth for this method (Wedel \& Kannan 2016). In order to develop this format in the future, the popularity and success of apparel ranges and products purchased through the interfaces could be measured through the tool. These platforms could also be enhanced considerably if they allowed consumer two-way communication with the developer or the retailer, for consumers to feedback openly on their experience of the size 
recommendation. Such communication may mitigate against future garment returns by understanding garment satisfaction. Thus, providing richer data and correctly allowing for the success of the interface to be considered beyond purchase intention.

\subsection{Fit Visualisation}

Fit visualisation interfaces are based around an avatar and tension maps where the consumer can assess how tight or loose a garment may be (Table 2). Results of this study showed that fit visualisation websites include more pictorial information than size recommendation websites (Gill 2015) (Table 2). Consumers can view images in contexts that simulate the garment on a body, though this may not be directly derived from the consumer. Through fit visualisation, retailers can provide the consumer with a more involved virtual experience as they can then gain a more realistic experience of the garment in relation to a body. Fit and sizing technologies must be consumer friendly, accurate, and realistic in their simulation of garments (Kim and LaBat 2013), though without using the actual consumer's body the visualisation may not realistically represent the fit experience.

\subsection{Fit Recommendation}

Fit recommendation websites enable consumers to try on different sizes of garments after entering basic measurements. Textual descriptions and basic images show the user the front and back of the garment on a standard dressed avatar. As women are more recently being guided in popular media through programmes such as 'What not to wear' (Bye and McKinney 2007), much of this culture persuades women to see the lack of practicality in keeping items that do not fit or suit them (Bye and McKinney 2007). Such advice provided in product purchase demonstrates an evident need for consumers to be guided in their fit decisions, often fulfilled by shop assistants or peers in bricks and mortar shopping. An inherent lack of direct access to personal contact with online fit recommendation interfaces, however may inhibit consumer perceptions of compatibility with the recommendations 
(Verhoef et al., 2009). Moreover, fit recommendation websites are limited to impersonal textbased descriptions. These descriptions do not take into account the highly subjective nature of body shape, fashion trends, social influences, and the complexity of personal preferences. Equally, basic images of avatars or garments may not show the difference between garment size and fit in enough detail for consumers to make an accurate assessment of suitability prior to purchase.

Table 2. Content Analysis Classification Typology

\begin{tabular}{|c|c|c|c|c|}
\hline Prim ary Cat egory & Explanation & $\begin{array}{l}\text { Leading Retailer } \\
\text { Examples }\end{array}$ & Theory in existing literature & $\begin{array}{c}\text { Theory applied to content } \\
\text { analysis }\end{array}$ \\
\hline $\begin{array}{l}\text { A. Size and Style } \\
\text { recommendation } \\
\mathrm{N}=10 \text { of total } \\
\text { websites } \\
\mathbf{5 0} \%\end{array}$ & $\begin{array}{l}\text { By entering basic measurements and } \\
\text { information about previous purchases } \\
\text { and garment fit, consumers are given a } \\
\text { recommended size prediction from a } \\
\text { particular retailer. Dressipi includes } \\
\text { style information and } \\
\text { recommendations. Fitbay includes size } \\
\text { recommendations of body doubles to } \\
\text { the user's measurements. Style } \\
\text { recommendations are provided } \\
\text { through browsing other users profiles. }\end{array}$ & $\begin{array}{l}\text { Dressipi, - M\&S, Shop } \\
\text { Direct, Topshop } \\
\text { Fits.me - M\&Co, } \\
\text { Hugo Boss, Coats } \\
\text { Viyella, LK Bennett. } \\
\text { Fitbay } \\
\text { Metail - Evans, F\&F, } \\
\text { House of Holland, } \\
\text { Little Mistress. }\end{array}$ & $\begin{array}{l}\text { Body esteem (Shin and Baytar } \\
\text { 2014) } \\
\text { Crowd power (Labrecque et al. } \\
\text { 2013, Yaoyuneyong et al. 2014) }\end{array}$ & $\begin{array}{l}\text { Personal recommendation and } \\
\text { exploration algorithms (Kapoor } \\
\text { et al. 2015; Ekstrand et al. } \\
\text { 2015) } \\
\text { Big Data (Gandomi and Haider } \\
\text { 2015) }\end{array}$ \\
\hline $\begin{array}{l}\text { B. Fit Visualisation } \\
N= \\
8 \text { of total websites } \\
42 \%\end{array}$ & $\begin{array}{l}\text { Metail and Qvit users can view } \\
\text { garments on personalised, computer } \\
\text { generated 3D avatars. Tightness and } \\
\text { looseness of garments are indicated } \\
\text { through heat/tension maps. Sheer and } \\
\text { colour changes can also be made. } \\
\text { Basic measurements such as height, } \\
\text { weight and bra size are used. Fitbay } \\
\text { users can view images of other users } \\
\text { wearing garments to depict how a } \\
\text { garment in their body shape/size } \\
\text { would fit. Users can comment on } \\
\text { garment choices of other users. }\end{array}$ & $\begin{array}{l}\text { Metail - Evans, F\&F, } \\
\text { House of Holland, } \\
\text { Little Mistress. }\end{array}$ & $\begin{array}{l}\text { Telepresence \& Perceived risk } \\
\text { (Shim and Lee 2011) } \\
\text { Augmented Reality } \\
\text { Virtual Reality } \\
\text { Image Interactivity Technology } \\
\text { (Fiore and Jin 2003, Fiore et al. } \\
\text { 2005, Lee et al. 2010). } \\
\text { Reactions to 3D Simulation (Kim } \\
\text { and LaBat 2012; Kim and Labat } \\
\text { 2013; Song and Ashdown 2015) }\end{array}$ & $\begin{array}{l}\text { Measurement methods (Power } \\
\text { et al. 2011) } \\
\text { Augmented Reality \& Virtual } \\
\text { Reality (Javornik 2016) } \\
\text { Big Data (Gandomi and Haider } \\
\text { 2015) }\end{array}$ \\
\hline $\begin{array}{l}\text { C. Fit } \\
\text { Recommendation } \\
\mathrm{N}=2 \text { of total } \\
\text { websites } \\
8 \%\end{array}$ & $\begin{array}{l}\text { Fits. Me includes text-based } \\
\text { descriptors of how a garment will fit } \\
\text { the consumer based on their } \\
\text { measurements mapped against retailer } \\
\text { size charts. }\end{array}$ & Fits.me-LK Bennett & $\begin{array}{l}\text { Clothing fit recommendation (Bye } \\
\text { et al. 2007) }\end{array}$ & $\begin{array}{l}\text { Big Data (Gandomi and Haider } \\
\text { 2015) }\end{array}$ \\
\hline
\end{tabular}

\section{Discussion}

Size and fit interfaces generate three areas of consideration. These are how the interface manages the customer relationship, how the user experiences the interface, and how 3D visualisation could enhance the consumer experience, especially in relation to mimicking actual shopping experiences. The following discussion deals primarily with these areas and then provides a means to unify them through a model. The model shows how the areas discussed through literature review are linked through a Venn diagram. 


\subsection{Online Customer Relationship Management}

Data-driven strategies are becoming more prevalent in the retail industry (Pousttchi \& Hufenbach, 2014; Watson, Worm, Palmatier, \& Ganesan, 2015) coupled with greater customer relationship management (Lemon and Verhoef 2016) as retailers use real-time analytics through streaming technology (Gandomi and Haider 2014). Therefore, tracking consumer-browsing data enables interfaces to provide targeted recommendations to the consumer and influence future merchandising strategy (Verhoef et al., 2010). Online fit and sizing technologies involve less social connectivity compared with in-store experiences such as virtual mirrors where social interactions are facilitated (Kim, Lee, Mun, \& Johnson, 2016). Fit satisfaction sits between the relationship of social acceptability and personal preference which should be explored in future research. Data from user reviews and experiences with the website, along with introducing social sharing into the interfaces, should feed into the future of fit and sizing technology, enabling retailers and developers to better position and target their tools. In the future, therefore, fit and sizing technologies should be designed to centrally enhance consumer trust in recommendation to provide an important tool for online purchasing. When considering trust, the consumers personal experience of the clothing item will heavily influence how valuable they perceive the interface and its subsequent success on product satisfaction (Yaoyuneyong et al. 2014; McKinney and Shin 2016). It is evident in existing studies that consumer product reviews are an important part of interface acceptance, purchase intention and future product satisfaction.

\subsection{User Experience}

The blurring of multiple channels is becoming prevalent to online retail strategies in order to enhance consumer browsing satisfaction with associated harmonious experiences (Beck \& Rygl 2015; Verhoef et al., 2015). The websites analysed were predominantly PC compatible with a few combining utilisation of multi-channels (Table 1), which suggests a need for better 
integration to mobile applications for a range of screen sizes. Petersen and Kumar (2009) state that returns are often higher in newer retailing channels e.g. pure-play (online only retailing) so applying the principles of Omni-channel to sizing and fit technologies should decrease the chance of returns through greater channel availability to return items. Greater availability of delivery and returns can increase pure-play retailer competitive advantage (Mintel 2017).

Augmented reality has played a large role in the development of virtual try-on in stores, through virtual mirrors in both product simulation and consumer try-on (Cho \& Schwarz 2012; Verhagen, Vonkeman, Feldberg, \& Verhagen, 2014). The areas of AR and virtual reality (VR) should not be dismissed when testing consumer responses to fit and sizing technologies due to general widespread consumer awareness of the retailing potential of such apps. Becoming more digitally integrated throughout shopping channels may increase consumer perceptions of innovative technology, enhancing perceptions of usefulness and utility to increase the potential for further consumer adoption (Shankar \& Yadav 2010). Gestural activity and increased use of AR may become more widely available in fit and sizing technologies in the future (Blázquez Cano, Perry, Ashman, \& Waite, 2017; Overmars \& Poels 2015), providing the consumer with a direct ability to experience the drape and handle of a fabric through digital means.

Fit and sizing technology integration is important to user experience of retail website flow. Website flow is a cognitive state experienced by a user when he or she is intrinsically absorbed within the content (Hausman and Siekpe 2009). McDowell et al. (2016) state that well designed website features assist with the conversion rate, which is measured by clickstream data analysis (Wedel \& Kannan, 2016). Based on this hypothesis being supported, the authors propose that flow experiences' impact on conversion should be carefully considered when implementing a fit and sizing technology within a retailer. A lack 
of consideration to the consumer's web journey through the online store and virtual fit interface may result in negative experiences. Unless digital fit and size flow experiences are managed across channels throughout the consumer's online decision-making process including time and effort required to use the interface, their success will be difficult to quantify.

\subsection{D Visualisation}

In order to simulate an accurate avatar, multiple measurements are required to produce a realistic presentation of the body (Gill 2015), the basic measurements suggested for virtual fit cover height, weight, and bra size, indicating the limited accuracy of fit visualisation tools. From content analysis, the lack of linearity between how visualisation interfaces have been developed is evident in the high proportion of interfaces using "other" combinations in addition to the height, weight, and bra-size input (Table 1). Additionally, the hedonic quality of an online experience is key to consumer acceptance and use (Poushneh and VasquezParraga 2017). Emphasising the need for aesthetics in 3D visuals. Fit and sizing visualisation websites could include more accurate and innovative methods of capturing body measurements influenced by 3D body scanning technology, though no consumer fit and sizing interfaces that are currently designed to be informed directly by a consumer's personal 3D body scan.

\subsection{Model Development}

Research must be extended to consumer reactions to fit in both virtual and real environments; using AR and VR and the influence of the bricks and mortar store, in order to sufficiently analyse the effectiveness of the fit and sizing technology from the consumer perspective. The previously fragmented areas of fit and sizing technologies must be combined for the platforms to be most successful in achieving all required ends from consumer to retailer satisfaction. The authors conclude that fit and sizing technologies must be driven by a 
combination of the three classification areas, as modern consumers require information from all to make a fully informed garment selection as depicted in the Omni-fit model (Figure 1).

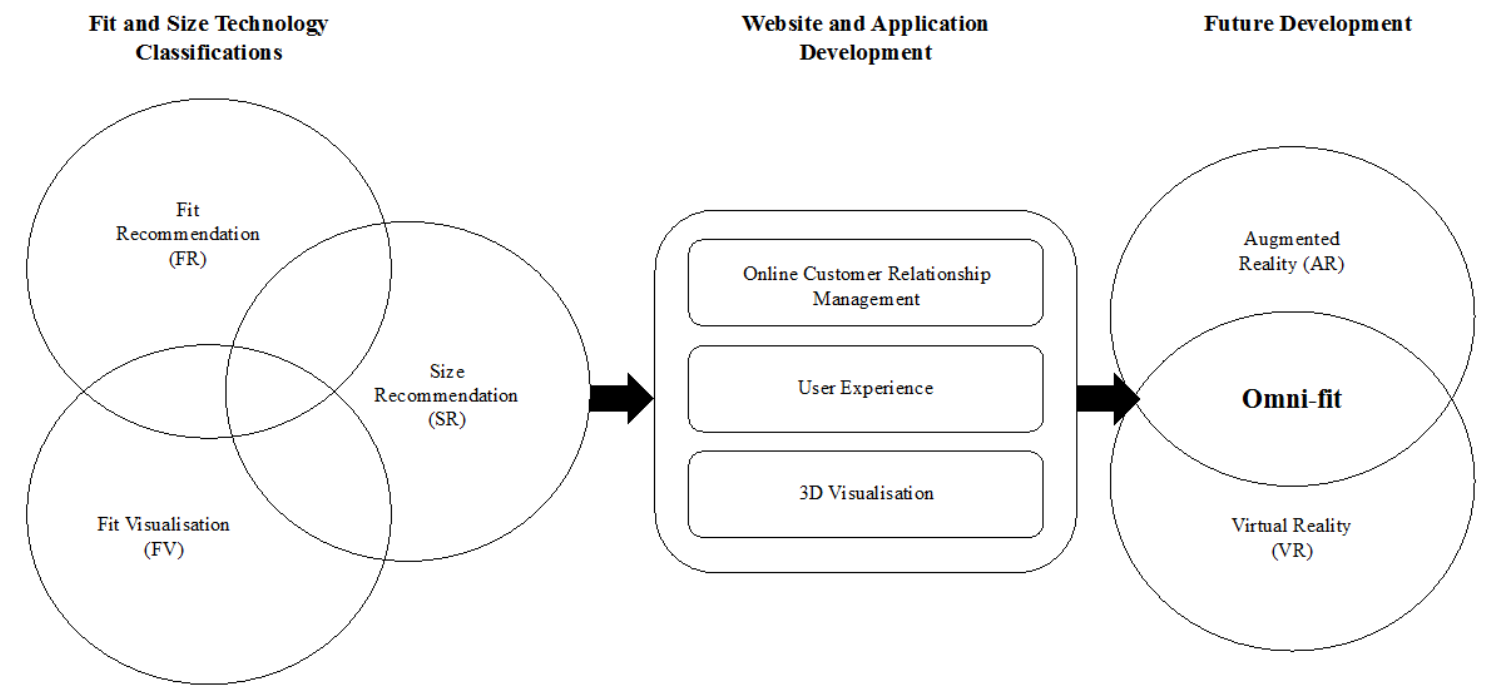

\section{Figure 1. Omni-fit model}

\section{Conclusion}

Whilst it is clear that significant developments have occurred in online retail interfaces, these developments remain varied in the level of consumer-enabled virtualisation and often cannot reproduce in-store experiences. Considerations are required regarding the integration of best practices from the interfaces to gain the most benefit for the retailer and consumers. As these interfaces develop and integrate, which blurs the evident boundaries of earlier interfaces as recognised by Gill (2015), it is clear updated classifications are required, but also that success will be best achieved through adopting a combination of all approaches which best replicates the multiple inputs of consumers product selection in store. This is through the distinction between the focus and feedback of existing channels shows a need to fully integrate the best elements of the interfaces to realise the most benefits for retailer and consumer. This research has identified and categorised the area of fit and sizing technologies available to consumers and provided clear directions for industry and practical applications. Existing interfaces show deficiencies in the technology and in the application of theories to consider consumers 
centrally within the fit and sizing tool, and to allow them to be fully catered in a way that replicates and enhances existing bricks-and-mortar purchases. Through the development of fit and sizing websites, customers' online decisions can be fully catered to, enhancing fit and sizing purchase satisfaction in online fashion retailing.

\subsection{Managerial Implications}

Most purchase-related research using fit and sizing technology stops short of investigating the post-purchase product experience, which like product reviews (Yaoyuneyong et al., 2014), are an important criterion used by consumers when making purchase decisions. Often purchase intention is the outcome variable in previous research. However, one way this may be initially tested in conjunction with previous methods, is through the availability of in-store virtual try-on or e-sizing tools, similar to the previous launch of virtual mirrors (Cho \& Schwarz, 2012). Outcomes could also include fit and sizing evaluations immediately after product selection, because the consumer can access the physical product immediately in store and evaluate it in accordance with his or her experience with the technology. By combining the digital and the physical retailing channels, fit and sizing technologies can be fully investigated in relation to their impact on consumer purchase satisfaction.

\subsection{Limitations and Future Research Directions}

The research identifies that the post-purchase consumption experience should be central to assessing the effectiveness of fit and sizing technologies on product purchase. This research demonstrates scope for a new dynamic, retailing environment through the emergence of size and fit augmented and virtual reality. The study only explores existing fit and style technologies, which are recognised as continually developing. As technologies such as 3D body scanning evolve, fit and sizing technologies will consequently develop increasing convenience for digital body measurement within the virtual fit platforms. However, the use of consumer data and it's increasing prevalence in the retailing industry must be considered 
and to what extent will consumers remain comfortable with having their information captured and shared (Watson et al. 2015). Areas identified through this research suggest studies should seek to establish the acceptable aspects of fit visualisation available and preferences from current interfaces to understand where developments should occur. Research is needed to understand how interfaces can increase sales conversion and reduce returns, especially purchase and return behaviour. Building from the analysis in this research, which provides an overview of the types of interfaces and documents their structures, it is possible to recognise strategies that will enable focused development and can successfully lead to online interfaces that satisfy consumer demands as well as retailer's requirements. 


\section{References}

Beck, M., and Crié, D. (2016). I virtually try it ... I want it! Virtual Fitting Room: A tool to increase on-line and off-line exploratory behavior, patronage and purchase intentions. Journal of Retailing and Consumer Services, 1-8.

Beck, N., and Rygl, D. (2015). Categorization of multiple channel retailing in Multi-, Cross-, and Omni-Channel Retailing for retailers and retailing. Journal of Retailing and Consumer Services, 27, 170-178.

Blázquez, M. (2014). Fashion Shopping in Multichannel Retail: The Role of Technology in Enhancing the Customer Experience. International Journal of Electronic Commerce, 18 (4), 97-116.

Blazquez Cano, M., Perry, P., Ashman, R., and Waite, K. (2017). The influence of image interactivity upon user engagement when using mobile touch screens. Computers in Human Behavior, 1-7 (Article in Press)

Bye, E., and McKinney, E. (2007). Sizing up the Wardrobe - Why We Keep Clothes That Do Not Fit. Fashion Theory. The Journal of Dress, Body and Culture, 11(4), 483-498.

Cho, H., and Schwarz, N. (2012). I Like Your Product When I Like My Photo: Misattribution Using Interactive Virtual Mirrors. Journal of Interactive Marketing, 26, 235-243.

Chung, J., and Rao, V. R. (2012). A General Consumer Preference Model for Experience Products: Application to Internet Recommendation Services. Journal of Marketing Research, 49, 289-305.

Davis, F.D. (1989). Perceived Usefulness, Perceived Ease of Use, and User Acceptance of Information Technology MIS Quarterly, 13 (3), 319-340.

Ekstrand, M. D., Kluver, D., Harper, F. M., and Konstan, J. A. (2015). Letting Users Choose Recommender Algorithms: An Experimental Study. Proceedings of the 9th ACM Conference on Recommender systems, 11-18. 
Ellis-Chadwick, F., Doherty, N., and Hart, C. (2002). Signs of change? A longitudinal study of Internet adoption in the UK retail sector. Journal of Retailing and Consumer Services, 9(2), 71-80.

Elo, S., and Kyngäs, H. (2008). The qualitative content analysis process. Journal of Advanced Nursing, 62(Cole 1988), 107-115.

Financial Times (2016). UK retailers count the cost of returns. Financial Times Online. [online]. Available from: https://www.ft.com/content/52d26de8-c0e6-11e5-846f79b0e3d20eaf [Accessed July 2016].

Gandomi, A., and Haider, M., (2014). Beyond the hype: Big data concepts, methods, and analytics. International Journal of Information Management, 35 (2), 137-144.

Gill, S. (2015). A review of research and innovation in garment sizing, prototyping and fitting. Textile Progress. 47 (1), 1-85.

Grogan, S., Gill, S., Brownbridge, K., Warnock, D. and Armitage, C. J. (2016). Women’s Long-Term Reactions to Whole-Body Scanning: A Mixed Methods Approach. Clothing and Textiles Research Journal, 34 (1), 61-73.

Hausman, A. V., and Siekpe, J. S. (2009). The effect of web interface features on consumer online purchase intentions. Journal of Business Research, 62 (1), 5-13.

Javornik, A. (2016). Augmented reality: Research agenda for studying the impact of its media characteristics on consumer behaviour. Journal of Retailing and Consumer Services, 30, 252261.

Kapoor, K., Kumar, V., Terveen, L., K. Joseph, A., and Schrater, P. (2015). 'I like to explore sometimes': Adapting to Dynamic User Novelty Preferences. The 2015 ACM conference on Recommender systems, 19-26.

Kim, D-E., and LaBat, K. (2013). Consumer experience in using 3D virtual garment simulation technology. Journal of the Textile Institute, 104 (8), 819-829. 
Kim, H-Y., Lee, J. Y., Mun, J. M., and Johnson, K. K.P. (2016). Consumer adoption of smart in-store technology: assessing the predictive value of attitude versus beliefs in the technology acceptance model. International Journal of Fashion Design, Technology and Education, 3266, 1-11.

Kim, I., and Kuljis, J. (2010). Applying content analysis to web based content. Journal of Computing and Information Technology, 18 (4), 369-375.

Kim, J., and Forsythe, S. (2008). Adoption of Virtual Try-on technology for online apparel shopping. Journal of Interactive Marketing, 22 (2), 45-59.

Krippendorff, K. (2004). Content Analysis: An Introduction to Its Methodology. 2nd ed. M. Seawell, Jill Meyers, C. Hoffman, \& J. Selhorst, eds. SAGE Publications.

Labrecque, L. I., vor dem Esche, J., Mathwick, C., Novak, T. P. and Hofacker, C. F. (2013). Consumer Power: Evolution in the Digital Age. Journal of Interactive Marketing, 27 (4), 257-269.

Lai, L. S. L. and To, W.M. (2014). Content Analysis of Social Media: A Grounded Theory Approach, 138-152.

Lee, H.H., Kim, J. and Fiore, A.M. (2010). Affective and Cognitive Online Shopping Experience: Effects of Image Interactivity Technology and Experimenting With Appearance. Clothing and Textiles Research Journal, 28 (2), 140-154.

Leeflang, P. S. H., Verhoef, P. C., Dahlström, P., and Freundt, T. (2014). Challenges and solutions for marketing in a digital era. European Management Journal, 32 (1), 1-12.

Lemon, K. N. and Verhoef, P. C. (2016). Understanding Customer Experience and the Customer Journey. Journal of Marketing, 80, 1-62.

Loker, S., Cowie, L., Ashdown, S. and Lewis, V. D. (2004). Female Consumers’ Reactions to Body Scanning. Clothing and Textiles Research Journal, 22, 151-160. 
Loker, S., Ashdown, S., and Carnrite, E. (2008). Dress in the Third Dimension: Online Interactivity and Its New Horizons. Clothing and Textiles Research Journal, 26 (2), 164-176. Marciniak, R., and Bruce, M. (2004). Identification of UK fashion retailer use of Web sites. International Journal of Retail \& Distribution Management, 32 (8), 386-393.

McDowell, W., Wilson, R., and Kile, C. (2016). An Examination of Retail Website Design and Conversion Rate. Journal of Business Research, 69 (11), 4837-4842.

McKinney, E. and Shin, E. (2016). Exploring Criteria Consumers Use in Evaluating Their Online Formal Wear Rental Experience: A Content Analysis of Online Reviews. Clothing and Textiles Research Journal, 34 (4), 272-286.

Merle, A., Senecal, S., and St-Onge, A. (2012). Whether and How Virtual Try-On Influences Consumer Responses to an Apparel Web Site. International Journal of Electronic Commerce, 16 (3), 41-64.

Mintel. (2017). Fashion Online - UK - June 2017. Mintel Oxygen. [online]. Available from: http://academic.mintel.com/display/839711/ [Accessed July 2017].

Overmars, S., and Poels, K. (2015). Online product experiences: The effect of simulating stroking gestures on product understanding and the critical role of user control. Computers in Human Behavior, 51, 272-284.

Pantano, E., and Gandini, A. (2016). Exploring the forms of sociality mediated by innovative technologies in retail settings. Computers in Human Behavior, 1-7.

Pantano, E., and Servidio, R. (2012). Modelling innovative points of sales through virtual and immersive technologies. Journal of Retailing and Consumer Services, 19 (3), 279-286.

Perry, A. (2016). Consumers' acceptance of smart virtual closets. Journal of Retailing and Consumer Services, 33, 171-177.

Petersen, J., and Kumar, V., (2009). Are Product Returns a Necessary Evil? Antecedents and Consequences. Journal of Marketing, 73, 35-51. 
Poushneh, A., and Vasquez-Parraga, A. Z. (2016). Discernible Impact of Augmented Reality on Retail Customer's Experience, Satisfaction and Willingness to Buy. Journal of Retailing and Consumer Services, 34, 229-234.

Pousttchi, K., and Hufenbach, Y. (2014). Engineering the value network of the customer interface and marketing in the data-rich retail environment. International Journal of Electronic Commerce, 18 (4), 17-41.

Power, E. Jess, Apeagyei, Phoebe R. and Jefferson, A. (2011). Integrating 3D Scanning Data and Textile Parameters in Virtual Clothing. Proceedings of the 2nd International Conference on 3D Body Scanning Technologies, 213-224.

Shankar, V., and Yadav, M. S. (2010). Emerging perspectives on marketing in a multichannel and multimedia retailing environment. Journal of Interactive Marketing, 24 (2), 55-57.

Shim, S. I., and Lee, Y. (2011). Consumer's perceived risk reduction by 3D virtual model. International Journal of Retail and Distribution Management, 39(12), 945-959.

Shin, E. and Baytar, F. (2013). Apparel Fit and Size Concerns and Intentions to Use Virtual Try-On: Impacts of Body Satisfaction and Images of Models’ Bodies. Clothing and Textiles Research Journal, 32 (1), 20-33.

Song, H. K. and Ashdown, S.P. (2012). Development of Automated Custom-Made Pants Driven by Body Shape. Clothing and Textiles Research Journal, 30 (4), 315-329.

Song, H. K. and Ashdown, S.P. (2015). Investigation of the Validity of 3-D Virtual Fitting for Pants. Clothing and Textiles Research Journal, 33 (4), 1-17.

Verhagen, T., Vonkeman, C., Feldberg, F., and Verhagen, P. (2014). Present it like it is here: Creating local presence to improve online product experiences. Computers in Human Behavior, 39, 270-280.

Verhoef, P. C., Kannan, P.K. and Inman, J. (2015). From Multi-Channel Retailing to OmniChannel Retailing. Journal of Retailing, 91 (2), 174-181. 
Verhoef, P. C., Lemon, K. N., Parasuraman, A., Roggeveen, A., Tsiros, M., and Schlesinger, L. A. (2009). Customer Experience Creation: Determinants, Dynamics and Management Strategies. Journal of Retailing, 85 (1), 31-41.

Verhoef, P. C., Venkatesan, R., McAlister, L., Malthouse, E. C., Krafft, M., and Ganesan, S. (2010). CRM in data-rich multichannel retailing environments: A review and future research directions. Journal of Interactive Marketing, 24 (2), pp.121-137.

Watson, G. F., Worm, S. Palmatier, R. W. and Ganesan, S. (2015). The Evolution of Marketing Channels: Trends and Research Directions. Journal of Retailing, 91(4), 546-568.

Wedel, M. and Kannan, P.K. (2016). Marketing Analytics for Data-Rich Environments. Journal of Marketing, 80, 97-121.

Yaoyuneyong, G., Foster, J. K. and Flynn, L. R. (2014). Factors impacting the efficacy of augmented reality virtual dressing room technology as a tool for online visual merchandising. Journal of Global Fashion Marketing, 5(4), 283-296. 